\title{
Impaired Skeletal Muscle Regeneration Induced by Macrophage Depletion could not be Improved by IGF-1 Injection
}

\section{Zhigang Zeng}

Shanghai University of Sport

Xiaoguang Liu

Guangzhou Sport University

\section{Linlin Zhao}

Shanghai University of Sport

\section{Lifang Zheng}

Shanghai University of Sport

\section{Yongzhan Zhou}

Shanghai University of Sport

\section{Peijie Chen}

Shanghai University of Sport

Weihua Xiao ( $\nabla$ xiao_weihua@163.com )

Shanghai University of Sport https://orcid.org/0000-0002-4447-9362

\section{Research}

Keywords: IGF-1, Macrophage depletion, Contused skeletal muscle, Regeneration, Fibrosis

Posted Date: July 29th, 2020

DOI: https://doi.org/10.21203/rs.3.rs-49599/v1

License: (c) (i) This work is licensed under a Creative Commons Attribution 4.0 International License. Read Full License 


\section{Abstract}

Background: Our previous study found that the depletion of macrophages led to the downregulation of insulin-like growth factor 1 (IGF-1) and impaired muscle regeneration after contusion. It was speculated that IGF-1 injection might improve the muscle repair impairment induced by macrophage depletion. Therefore, we explored whether injected IGF-1 plays an important role in improving impaired muscle repair.

Methods: Animal models of muscle contusion and macrophage depletion with and without IGF-1 injection were established with gastrocnemius muscles in mice. Comprehensive histomorphological and genetic analyses were performed on the contused muscles after macrophage depletion and IGF-1 injection.

Results: IGF-1 injection could promote the partial recovery of macrophage subpopulations (CD206) and the expression of vascular endothelial growth factor (VEGF) and angiopoietin -1 (Angpt-1) after macrophage depletion. However, after IGF-1 injection, the levels of regenerative myofibers and fibrosis, as well as the levels of proinflammatory macrophages (CD68) and the expression of muscle differentiation factor (MyoD), myogenin, VEGF and Angpt-1 still did not return to the levels found after simple muscle contusion in the late stage of repair.

Conclusions: These results suggest that IGF-1 injection did not improve the impaired regeneration and repair of contused muscles induced by macrophage depletion.

\section{Introduction}

Contusion was one of the most common injuries in sports. After muscle contusion, the repair process of muscle regeneration or fibrosis occurs in the injured tissue. Many repair-related factors, such as myogenic regulatory factors, muscle regeneration-related regulatory factors, angiogenesis regulatory factors, granulocytes, and macrophages, also have corresponding changes (1). In many previous studies, through exogenous changes in the above-mentioned factors, such as hyperbaric oxygen, immunocytes, stem cell transplantation, fibrosis inhibitors, and muscle regeneration-related growth factors, researchers have attempted to improve muscle regeneration and repair (2-6).

Our previous study found that the depletion of macrophages led to the downregulation of IGF-1 and impaired muscle regeneration $(7,8)$. Furthermore, some studies indicated that macrophage depletion impaired regeneration and repair following muscle injury (9-11). Moreover, some studies also showed that after muscle injury, myeloid cell-derived IGF-1 could drive the proliferation of activated satellite cells and promote a shift in the macrophage phenotype from an M1-biased to an M2-biased population. Then, nonmyeloid, nonmuscle cells-derived IGF-1 could promote myoblast differentiation into myotubes and subsequent growth into muscle fibers $(12,13)$. Therefore, it was speculated that the impairment of muscle regeneration after macrophage depletion might be related to the downregulation of IGF-1 induced by macrophage depletion. 
Therefore, we hypothesized that IGF-1 injection might improve the muscle regeneration impairment induced by macrophage depletion to a certain extent. To explore this concept, we constructed a muscle contusion and macrophage depletion mouse model and injected IGF-1 into the contused muscle of the mice. The histomorphology, fibrosis, and levels of macrophages and expression of macrophage subtype surface markers, myogenic regulatory factors, and angiogenesis regulatory factors were tested in contused skeletal muscle.

\section{Methods}

Animals

A total of 140 male wild-type mice (specific pathogen-free C57BL/6; purchased from Shanghai SLAC Laboratory Animal Co., Ltd, Shanghai, China) between 7 and 9 weeks of age and weighing between 18.7 and $23.1 \mathrm{~g}$ were housed under pathogen-free conditions at a constant temperature of $25^{\circ} \mathrm{C}$, and $\sim 50 \%$ relative humidity, with a light-dark cycle of 12:12 hours and free access to pellet food and water. All experimental protocols were approved by the Ethics Review Committee for Animal Experimentation of Shanghai University of Sports (Reference No. 2014025).

Experimental design

The mice were randomly assigned to 1 of 3 groups according to the following treatment: (1) intraperitoneal injection (ip) of phosphate-buffered saline (PBS) liposomes and intramuscular injection (im) of PBS (contusion and placebo treatment in the Cp group; $n=60$ ); (2) clodronate liposomes (ip) (contusion and macrophage depletion in the CD group; $\mathrm{n}=60$ ); and (3) clodronate liposomes (ip) and IGF1 (im) (contusion with macrophage depletion and IGF-1 injection in the CDI group; $n=48$ ). In the $C, C D$ and CDI groups, each mouse suffered bilateral contusions of the gastrocnemius muscles (GMs), except for the Con group. In the $\mathrm{Cp}$ group, the mice in the Con group (sampled before contusion) had no contusion but received placebo treatment (ip and im), whereas the mice in the $1 \mathrm{~d}, 3 \mathrm{~d}, 7 \mathrm{~d}$, and $14 \mathrm{~d}$ groups (sampled at the following time points after contusion: $1 \mathrm{~d}, 3 \mathrm{~d}, 7 \mathrm{~d}$, and $14 \mathrm{~d}$ ) received contusions and placebo injection. In the CD group, the mice in the Con group had no contusions but received macrophage depletion, whereas the mice in the $1 \mathrm{~d}, 3 \mathrm{~d}, 7 \mathrm{~d}$, and $14 \mathrm{~d}$ groups received contusions and macrophage depletion. In the CDI group, the mice in the $1 \mathrm{~d}, 3 \mathrm{~d}, 7 \mathrm{~d}$, and $14 \mathrm{~d}$ groups received contusions combined with macrophage depletion and IGF-1 injection. However, the mice of the Con group of the CDI group received the same treatment as those of the Con group of the CD group; therefore, the Con data used for the $C D$ and CDI groups were the same. In the Con group, $1 d, 3 d, 7 d$, and $14 d$ groups, 12 mice per group were euthanized and evaluated (histology: $n=4$; gene expression: $n=8)($ Scheme 1).

Animal model of skeletal muscle contusion

Skeletal muscle contusion of bilateral GMs in the mice was created as described previously (14-16). The animals were anesthetized using $5 \%$ chloral hydrate $(0.01-0.02 \mathrm{ml} / \mathrm{g}$ body weight) by intraperitoneal injection. Each mouse's hind limb was positioned by extending the knee and plantarflexing the ankle $90^{\circ}$. 
A stainless steel ball $(16.8 \mathrm{~g}$, diameter: $15.9 \mathrm{~mm}$ ) was dropped from a height of $125 \mathrm{~cm}$ through a tube (interior diameter of tube: $16 \mathrm{~mm}$ ) onto the impactor (a surface of $28.26 \mathrm{~mm}^{2}$ ) that made contact with the midportion of GMs $(17,18)$. This technique simulated a high-energy blunt injury that left a large hematoma, which is usually followed by muscle regeneration, thus closely mimicking the initial inflammatory response and subsequent muscle repair observed in humans $(4,19-21)$. The mice were sacrificed, and the GMs were harvested at different time points after contusion (Con, $1 \mathrm{~d}, 3 \mathrm{~d}, 7 \mathrm{~d}$, and 14 d) for evaluating the repair of contused muscles (Scheme 1). To illustrate the characteristics of subsequent changes, with reference to previous studies $(1,12)$ and the status of this study, the first and third days after contusion were defined as the initial stage of injury repair, the seventh day as the interim stage of repair, and the fourteenth day as the late stage of repair.

Injection of liposomes

For macrophage depletion, the mice were treated with clodronate-containing liposomes $(5 \mathrm{mg} / \mathrm{ml})$ or PBS-containing liposomes (purchased from Liposoma B.V., Amsterdam, Netherlands) given by intraperitoneal injection $2 \mathrm{~d}$ before GM contusion ( $0.2 \mathrm{ml}$ ip) and then on $0 \mathrm{~d}, 3 \mathrm{~d}, 6 \mathrm{~d}, 9 \mathrm{~d}$, and $12 \mathrm{~d}$ after GMs contusion $(0.1 \mathrm{ml}$ ip) as previously described (22-24). Flow cytometry using macrophage marker antibodies (F4/80 and CD-11b) was used to verify the extent of macrophage depletion. Verification results can be found in preresearch papers. The data showed that macrophages were significantly reduced by at least $55 \%$ in the clodronate liposomes-treated mice as compared to the control mice (24, 25).

Injection of IGF-1

For IGF-I (purchased from R\&D Systems, Inc.) treatment, each mouse in the CDI group received an intramuscular injection of IGF-I ( $0.5 \mu \mathrm{g} / 20 \mu \mathrm{l} /$ muscle; R\&D Systems, Inc., USA; Lot: DGV2514072) into the bilateral GMs 3 consecutive times $(0 \mathrm{~d}, 1 \mathrm{~d}$, and $2 \mathrm{~d}$ ) after contusion. In the $\mathrm{Cp}$ and CD groups, the muscles were injected only with PBS $(0.01 \mathrm{M} / 20 \mu \mathrm{l} /$ muscle). The protocol was modified based on previously described studies (26-28).

Histomorphological evaluation of muscle regeneration and fibrosis

After the mice were euthanized at $14 \mathrm{~d}$ after contusion, bilateral gastrocnemius muscles were snap immersed at $4{ }^{\circ} \mathrm{C}$ in $4 \%$ paraformaldehyde (precooled in the refrigerator) for 24 hours until they were routinely paraffin-embedded and sectioned. Serial cross-sections of 4- $\mu \mathrm{m}$ thickness were stained with hematoxylin and eosin to evaluate the number, area and diameter of regenerative myofibers in the images obtained using a BX53 optical microscope that was connected to a spot image capture system DP80 digital camera (Olympus Corporation). The total number of centrally nucleated myofibers, which represented the regenerating myofibers, was quantified by counting the centrally nucleated myofibers in 3 representative $200 \times$ high-powered fields (hpf) from each sample as previously described (27, 29-31). The total areas (the sum of the cross-sectional area) of the regenerating myofibers were measured. 
Moreover, the total diameter (the sum of the minor axis diameters) of the regenerating myofibers was measured as previously described $(24,29)$.

A Masson modified trichrome stain kit was used to stain the fibrotic tissue within the injury sites at $14 \mathrm{~d}$ after contusion. After staining, the fibrotic areas of $40 \times$ low-powered images that included a complete area of damage were calculated to estimate the areas of new fibrotic tissue using Image-Pro Plus 6.0 (Media Cybernetics, Inc.) as previously described $(27,29)$. Then, the results of the control group and each of the treatment groups were compared.

Immunofluorescence staining

Immunofluorescence staining was performed to detect MyoD and myogenin at $14 \mathrm{~d}$ after contusion using the modified protocols of Abcam. GM sections were incubated with $10 \%$ normal goat serum (NGS) blocking buffer for 2 hours at room temperature (RT) and with the MyoD (Santa Cruz, 1:100) and myogenin (Abcam, 1:100) primary antibodies overnight at $4{ }^{\circ} \mathrm{C}$. The sections were washed three times with Tris-buffered saline (TBS) for 5 min per wash and then incubated with a goat anti-rabbit lgG secondary antibody (Abcam, 1:500) for 1 hour at RT. After washing three times with TBS, the sections were incubated with 4, 6-diamidino-2-phenylindole (DAPI, 1:500, Beyotime Biotech, Co., Ltd.) for 5 min at RT, washed three times with TBS and then sealed with an anti-quenching sealing solution. Using a $20 \times$ lens objective (LSM700, Zeiss), the images were captured for each muscle section. The average immunofluorescence intensity was semiquantitatively analyzed using ImageJ 1.52 (National Institutes of Health, United States) and Image-Pro Plus 6.0 (Media Cybernetics, Inc.).

RNA isolation and Reverse-Transcription Polymerase Chain Reaction (RT-PCR)

Total RNA was isolated from the GMs in TRIzol Reagent (Invitrogen, Thermo Fisher Scientific) using a modified guanidinium isothiocyanate- $\mathrm{CsCl}$ method, and then equal amounts of RNA ( $2 \mu \mathrm{g})$ were used to generate cDNA using the RevertAidTM First Strand cDNA Synthesis Kit (Invitrogen, Thermo Fisher Scientific) (32). The reaction was carried out at $25^{\circ} \mathrm{C}$ for $5 \mathrm{~min}$ followed by another $60 \mathrm{~min}$ at $42^{\circ} \mathrm{C}$ and was terminated by the deactivation of the enzyme at $70{ }^{\circ} \mathrm{C}$ for $5 \mathrm{~min}$. Control reactions lacking either reverse transcriptase or template were included to assess the carry-over of genomic DNA and nonspecific contamination (25).

Relative Quantitative Real-time PCR (Rt-qPCR)

Real-time quantitative PCR was performed in a StepOnePlus PCR-Cycler (Life Technologies) using ChamQ Universal SYBR qPCR master mix (Vazyme Biotech Co., Ltd) for mouse F4/80, CD68, CD163, CD206, MyoD, Myf5, myogenin, Myf6, HIF-1a, VEGF, Angpt-1 and GAPDH (each primer used for Rt-qPCR is in Table 1). The reactions were carried out with initial denaturation at $95^{\circ} \mathrm{C}$ for $30 \mathrm{sec}, 40$ cycles of denaturation at $95^{\circ} \mathrm{C}$ for $10 \mathrm{sec}$ and annealing/extension at $60^{\circ} \mathrm{C}$ for $30 \mathrm{sec}$, and melting curve generation (at $95^{\circ} \mathrm{C}$ for $15 \mathrm{sec}, 60^{\circ} \mathrm{C}$ for $60 \mathrm{sec}$ and $95^{\circ} \mathrm{C}$ for $15 \mathrm{sec}$ ). The cycle threshold (CT, the number of cycles to reach the threshold of detection) was determined for each reaction, and the levels of 
the target mRNAs were quantified relative to the mRNA level of the Con group in the Cp group as baseline with GAPDH as the housekeeping gene using the $2^{-\triangle \triangle C T}$ method $(25,33)$.

\section{Statistical analysis}

All data were presented as $\bar{\chi} \pm S E M$ and analyzed using IBM SPSS Statistics (version 23, IBM, Armonk, NY, USA). Factorial analysis of Multiway ANOVA was performed to determine if there were any effects of the interactions between any two factors among time, depletion and IGF-1. If any significant effects were evident $(\rho<0.05)$, one-way ANOVA was used to compare the significant differences in different time points after contusion (34). Post hoc multiple comparisons were performed using the Scheffe test if equal variances were assumed or using the Games-Howell test if equal variances were not assumed. To compare the significant differences among different treatment groups at the corresponding time point, an independent-samples t-test was used if there were no group-time interactions. Otherwise, one-way ANOVA was still used. Differences between values were considered statistically significant when $\rho$-values were less than 0.05 .

Table 1

Primers used for Rt-qPCR

\begin{tabular}{|c|c|c|}
\hline Target gene & Forward primer sequences & Reverse primer sequences \\
\hline $\mathrm{F} 4 / 80$ & 5'-AACATGCAACCTGCCACAAC-3' & 5'-TTCACAGGATTCGTCCAGGC-3' \\
\hline CD68 & 5'-CAAAGCTTCTGCTGTGGAAAT-3' & 5'-GACTGGTCACGGTTGCAAG-3' \\
\hline CD163 & 5'-GCAAAAACTGGCAGTGGG-3' & 5'-GTCAAAATCACAGACGGAGC-3' \\
\hline CD206 & 5'-GGATTGTGGAGCAGATGGAAG-3' & 5'-CTTGAATGGAAATGCACAGAC-3' \\
\hline MyoD & 5'-GAGCGCATCTCCACAGACAG-3' & 5'-AAATCGCATTGGGGTTTGAG-3' \\
\hline Myf5 & 5'-GGAATGCCATCCGCTACATT-3' & 5'-CGTCAGAGCAGTTGGAGGTG-3' \\
\hline Myogenin & 5'-CCAGTACATTGAGCGCCTAC-3' & 5'-ACCGAACTCCAGTGCATTGC-3' \\
\hline Myf6 & 5'-CCTCAGCCTCCAGCAGTCTT-3' & 5'-ТТСТССАССАССТССТССАС-3' \\
\hline HIF-1a & 5'-GGCGAGAACGAGAAGAAAAAGATGA - 3' & 5'- GCTCACATTGTGGGGAAGTGG - 3' \\
\hline VEGF & 5'- TAACAGTGAAGCCCTGGAGTG - 3' & 5'- TTTGACCCTTTCCCTTTCCTCG-3' \\
\hline Angpt-1 & 5'- AACCGGATTCAACATGGGCA - 3' & 5'- GAGCGTTGGTGTTGTACTGC - 3' \\
\hline GAPDH & 5'-ACTCCACTCACGGCAAATTC-3' & 5'-TCTCCATGGTGGTGAAGACA-3' \\
\hline
\end{tabular}

\section{Results}

Effect of clodronate-containing liposomes on macrophage in injured skeletal muscle 
Compared with simple muscle contusion, total macrophages (F4/80 mRNA) after macrophages depletion was significantly inhibited ( $\rho<0.05$, Fig. 1 a and Fig. 2$)$. Consistent with our previous studies, the results showed that macrophages were effectively depleted (25). Even so, the cellular immune response after contusion with macrophage depletion and IGF-1 injection, was improved to some extent, and total macrophages (F4/80 mRNA), proinflammatory macrophages (CD68 mRNA), anti-inflammatory macrophages (CD163 and CD206 mRNA) increased significantly $(\rho<0.05$, Fig. 1a-d and Fig. 2), detailed in the undermentioned results and discussion of 'Macrophages and Their Subtypes'.

Effect of IGF-1 injection on muscle regeneration after macrophage depletion in contused skeletal muscle

The number, area, and diameter of centrally nucleated myofibers at the site of injury were measured and compared in the $\mathrm{Cp}, \mathrm{CD}$ and $\mathrm{CDI}$ groups at $14 \mathrm{~d}$ after contusion. The sums of the numbers $(348 \pm 37.15$ vs. $706 \pm 63.64, \rho<0.05)$, areas ( $36055 \pm 7157.94$ vs. $103462 \pm 17145.27, \rho<0.01)$, and diameters (3319 \pm 503.19 vs. $7927 \pm 991.20, \rho<0.05$ ) of regenerating myofibers in the CD group were significantly reduced compared with those in the $\mathrm{Cp}$ group. However, compared with the sums of the numbers, areas and diameters of regenerating myofibers in the CD group, after IGF-1 injection, those in the CDI group were not increased significantly $(\rho>0.05$, Fig. 3$)$.

Effect of IGF-1 injection on myogenic regulatory factors after macrophage depletion in contused skeletal muscles

Compared with the expression levels before contusion in the $\mathrm{Cp}$ group, those of MyoD, myogenic factor 5 (Myf5) and myogenin mRNA before contusion in the CD and CDI groups were increased significantly $(\rho<$ 0.01 , Fig. 4a-c). Moreover, compared with the expression levels at the corresponding time point in the $\mathrm{Cp}$ group, those of MyoD mRNA at $3 \mathrm{~d}$, Myf 5 mRNA at $3 \mathrm{~d}$ and $14 \mathrm{~d}$, myogenin mRNA at $14 \mathrm{~d}$ and myogenic factor 6 (Myf6) mRNA at $1 \mathrm{~d}$ and $3 \mathrm{~d}$ in the CD group were increased significantly $(\rho<0.05$, Fig. 4a-d). Moreover, the expression of MyoD and myogenin mRNA at $14 \mathrm{~d}$ in the CDI group also increased significantly $(\rho<0.001$, Fig. $4 a, c)$. The immunofluorescence staining also showed similar results, which showed that the expression of MyoD and Myogenin in CDI group was not reduced significantly compared with $C D$ group 14 days after injury $(\rho>0.05$, Fig. 5$)$. Furthermore, compared with the expression levels in the CD group, after IGF-1 injection, those of MyoD mRNA at $1 \mathrm{~d}, 7 \mathrm{~d}$ and $14 \mathrm{~d}$ were increased significantly $(\rho<0.05)$, but Myf 5 mRNA at $3 d, 7 d$ and 14 d was reduced significantly $(\rho<0.01$, Fig. $4 a, b)$.

Effect of IGF-1 injection on muscle fibrosis after macrophage depletion in contused skeletal muscle

The areas of fibrotic tissue at the site of injury were measured and compared in the $\mathrm{Cp}, \mathrm{CD}$ and $\mathrm{CDI}$ groups at $14 \mathrm{~d}$ after contusion. The areas of fibrotic tissue in the CD group (3048 \pm 857.20 vs. $496 \pm$ $162.06, \rho<0.05)$ were increased significantly compared with those in the Cp group. However, compared with the areas of fibrotic tissue in the CD group, after IGF-1 injection, those in the CDI group were not reduced significantly ( $\rho>0.05$, Fig. 6$)$. 
Effect of IGF-1 injection on macrophages and their subtypes after macrophage depletion in contused skeletal muscles

Compared with the expression levels at the corresponding time point in the $\mathrm{Cp}$ group, the expression of F4/80 mRNA in the CD group at $3 d, 7 d$, and $14 d$ after contusion was reduced significantly $(\rho<0.05$, Fig. 1a and Fig. 2). Namely, total macrophages (F4/80 mRNA) after macrophage depletion were significantly inhibited. However, compared with the expression levels in the CD group, after IGF-1 injection, the expression of F4/80 mRNA in the CDI group at $3 \mathrm{~d}, 7 \mathrm{~d}$ and $14 \mathrm{~d}$ after contusion was increased significantly ( $\rho<0.05$, Fig. 1 a and Fig. 2); even the expression of F4/80 mRNA in the CDI group at $3 \mathrm{~d}$ and $14 \mathrm{~d}$ after contusion was higher than that in the Cp group ( $\rho<0.05$, Fig. 1a).

However, compared with that in the CD group, after IGF-1 injection, the expression of CD68 mRNA in any stages of repair in the CDI group had no significant change $(\rho>0.05)$, whereas the expression of CD163 mRNA at $3 d$ and CD206 mRNA at $1 d$ and $3 d$ in the CDI group was increased significantly $(\rho<0.01$, Fig. 1b-d). Even compared with the expression levels in the Cp group, those of CD68 and CD206 mRNA at $14 \mathrm{~d}$ in the CDI group were increased significantly $(\rho<0.05)$, whereas the expression of CD163 mRNA at $14 \mathrm{~d}$ in the CDI group was reduced significantly $(\rho<0.01$, Fig. $1 \mathrm{~b}-\mathrm{d})$. Namely, the increases in macrophages after IGF-1 injection showed different degrees of increase in M1 and M2 macrophages.

Effect of IGF-1 injection on angiogenesis regulatory factors after macrophage depletion in contused skeletal muscles

The expression of hypoxia inducible factor - 1a (HIF-1a) and VEGF mRNA before contusion in the CD and CDI groups was increased significantly compared with those before contusion in the Cp group $(\rho<0.05$, Fig. 7a, b). Compared with the expression levels in the Con group of the CD group, the expression of HIF1a mRNA at $1 \mathrm{~d}$ and $3 \mathrm{~d}$ and Angpt-1 mRNA at $3 \mathrm{~d}$ and $7 \mathrm{~d}$ in the CD group were increased significantly ( $\rho$ $<0.05$ ), but those of VEGF mRNA at $1 \mathrm{~d}, 3 \mathrm{~d}, 7 \mathrm{~d}$ and $14 \mathrm{~d}$ and Angpt-1 mRNA at $14 \mathrm{~d}$ were reduced significantly $(\rho<0.05$, Fig. 7a-c).

Moreover, compared with the expression levels at the corresponding time point in the Cp group, those of HIF-1a mRNA at $1 \mathrm{~d}$ and VEGF mRNA at $1 \mathrm{~d}$ in the CD group were increased significantly $(\rho<0.01)$, but those of VEGF mRNA at $14 \mathrm{~d}$ and Angpt-1 mRNA at $1 \mathrm{~d}, 3 \mathrm{~d}, 7 \mathrm{~d}$ and $14 \mathrm{~d}$ in the CD group were reduced significantly $(\rho<0.01$, Fig. 7a-c).

Furthermore, compared with the expression levels in the CD group, those of HIF-1 a mRNA at $1 d, 3 d, 7 d$ and $14 d$ and VEGF mRNA at $1 d$ in the CDI group were reduced significantly $(\rho<0.05)$, but the expression levels of VEGF mRNA at $14 \mathrm{~d}$ and Angpt-1 mRNA at $1 \mathrm{~d}, 3 \mathrm{~d}, 7 \mathrm{~d}$ and $14 \mathrm{~d}$ in the CDI group were increased significantly $(\rho<0.001$, Fig. 7a-c). In addition, compared with the expression levels in the Cp group, those of HIF-1a, VEGF and Angpt-1 mRNA at $14 d$ in the CDI group were reduced significantly $(\rho<0.001$, Fig. 7ac).

\section{Discussion}


IGF-1 injection did not improve the reduced regenerative myofibers induced by macrophage depletion in contused muscles

In the current study, the regenerative myofibers in contused muscles after macrophage depletion were fewer than those after simple muscle contusion (Fig. 3). This result was consistent with our previous studies $(7,8,25,35)$ and those of others $(24,36,37)$. Namely, macrophage depletion impaired injured muscle regeneration and delayed muscle repair, confirming that macrophages were the necessary functional requirement for efficient repair $(9,11,38,39)$. However, after IGF-1 injection, impaired muscle regeneration did not improve (Fig. 3). Although IGF-1 supplementation could improve injured muscle regeneration by activating the proliferation of satellite cells and promoting the transformation of the macrophage phenotype from $M 1$ to $M 2(5,12,26)$, in contrast, activated macrophages could secrete cytokines such as IGF-1 $(9,12,26,40,41)$. Macrophages and IGF-1 need to achieve corresponding spatiotemporal coordination to play their appropriate roles. In this study, IGF-1 injection did not improve the impairment of muscle regeneration induced by macrophage depletion. This might be because, if the macrophages had been depleted continuously, IGF-1 supplementation could not function as the whole remedy for the vital role of macrophages in muscle repair. The corresponding mechanism will be analyzed and discussed in the aftermentioned changes of muscle satellite cell proliferation, differentiation markers and macrophage subsets.

IGF-1 injection did not improve the delayed repair of contused muscles induced by macrophage depletion as determined by MRFs increases, especially in the late stage of repair

Myogenic regulatory factors (MRFs) regulate the proliferation and differentiation of skeletal muscle cells; MyoD and Myf5 act as determining factors in the initial stage of myogenic differentiation, and their expression triggers the production of myogenin and Myf6, which act to permit terminal differentiation of myoblasts into myocytes, leading to fused myotubes (42-45). Through macrophage depletion before muscle contusion, the mRNA expression of MyoD, Myf5, and myogenin in healthy muscle tissue was increased significantly (Fig. 4a-c). This might be because macrophage depletion produced changes in basic levels of anti-inflammatory cytokines, which lead to changes in these MRFs in the initial stage of repair.

Moreover, compared with the expression levels after simple muscle contusion, those of MyoD, Myf5, myogenin, and Myf6 were increased significantly at different time points after macrophage depletion (such as Myf5 and myogenin in the late stage) (Fig. 4a-d). The enhancement of myoblast proliferation and differentiation, especially in the late stage of repair, suggests that muscle regeneration and repair were delayed by macrophage depletion. In addition, the increased mRNA and protein expression of MyoD and myogenin at $14 \mathrm{~d}$ postinjury after IGF-1 injection also suggests that the repair of contused muscle was still delayed even after IGF-1 injection (Fig. 4a, c; Fig. 5).

Furthermore, compared with that after macrophage depletion, the mRNA expression of MyoD after IGF-1 injection in the interim and late stages of repair was increased significantly (Fig. 4a). In contrast, the mRNA expression of Myf5 after IGF-1 injection was significantly reduced (Fig. 4b). Namely, IGF-1 injection 
could reduce the increase in Myf5 induced by macrophage depletion. In light of these results, we speculated that IGF-1 might coordinate the proliferation and initial differentiation of myoblasts through both MyoD and Myf5 to make the response moderate $(44,46,47)$.

IGF-1 injection did not improve the aggravated muscle fibrosis induced by macrophage depletion in contused muscles

In previous studies, macrophages, including distinct macrophage subpopulations, were found to act in both profibrotic and antifibrotic capacity (48). Most studies suggest that proinflammatory macrophages are essential mediators of fibrosis by managing debridement $(39,49)$, while anti-inflammatory macrophages could ameliorate fibrosis by antagonizing proinflammatory macrophages, reducing extracellular matrix production and competing against neighboring immune cells for nutrients $(38,39$, 50-53). In the current study, macrophage depletion resulted in a significant increase in fibrosis after muscle contusion (Fig. 6). This might be because proinflammatory macrophage depletion in the initial stage greatly diminished the inflammatory response, reduced debridement and thus led to less regeneration and repair. Additionally, the more important reason might be that the anti-inflammatory macrophage decline, which caused by the depletion of anti-inflammatory macrophage and the initial proinflammatory macrophage depletion, weakened the benefits of inhibiting fibrosis. Similarly, due to the anti-inflammatory macrophage decline, increased fibrosis was not improved by IGF-1 injection (Fig. 6). Although IGF-1 injection promoted partial recovery of anti-inflammatory macrophages (CD206) at the late stage of repair, the improvement effect of IGF-1 on contused muscle regeneration and fibrosis might be related to other macrophage subpopulations or factors, which is detailed in the following discussion.

IGF-1 injection could not facilitate the coordination among macrophages after macrophage depletion, thereby not improving the regeneration and repair of contused muscles

Total macrophages (F4/80 mRNA) after macrophages depletion were significantly inhibited compared with those after simple muscle contusion (Fig. 1a and Fig. 2). Nonetheless, through IGF-1 injection, the cellular immune response after contusion was improved to a certain extent (5). However, compared with that after simple muscle contusion, the levels of proinflammatory macrophages (CD68 mRNA) after macrophage depletion or after IGF-1 injection in the late stage of repair were increased significantly (Fig. 1b). This result indicated not only that macrophage depletion led to the increased muscle inflammation and delayed repair of contused muscle but also that IGF-1 injection did not improve it. Moreover, there was mostly the recovery of anti-inflammatory macrophages (CD163 and CD206 mRNA) in the initial stage of repair (Fig. 1c, d) because IGF-1 could promote a shift in the macrophage phenotype from $M 1$ to $M 2(12,54)$.

However, in the late stage of repair (at $14 \mathrm{~d}$ postinjury), total macrophages (F4/80 mRNA) after IGF-1 injection were higher than those after both macrophage depletion and simple muscle contusion, but the mRNA levels of CD68 and CD206 macrophages after IGF-1 injection were higher only than that after simple muscle contusion, and the mRNA levels of CD163 macrophages were lower than that after simple muscle contusion (Fig. 1a-d). These results suggest that the increase of these anti-inflammatory 
macrophages was not as significant as that of total macrophages during the recovery of macrophages. Given this, we speculated that other macrophage subpopulations might be involved in functional recovery in the interim and late stages of repair, not just these macrophages (CD163 and CD206). Therefore, although IGF-1 injection could modulate the inflammatory response and change the muscle regeneration and repair environments by increasing some types of macrophages $(5,38,55,56)$, IGF- 1 injection combined with macrophage depletion could not facilitate the coordination among macrophages and thus did not improve muscle regeneration and repair.

IGF-1 injection partly improved the inhibition of angiogenesis regulatory factors induced by macrophage depletion but could not improve the impaired regeneration and repair of contused muscles

HIF-1a can promote the regeneration and repair of injured tissue by activating VEGF and Angpt-1 (5760). VEGF and Angpt-1 play essential roles in angiogenesis, vascular regeneration and development and contribute to vessel maturation and stability (60-63). In the current study, compared with that after simple muscle contusion, the increased mRNA expression of HIF-1a and VEGF in the initial stage of repair after macrophage depletion (Fig. 7a, b) might be because macrophage depletion mimicked hypoxia and triggered an increase in HIF-1a, thereby upregulating VEGF $(59,64-67)$. However, VEGF mainly came from white blood cells in plasma $(34,68,69)$; thus macrophage depletion led to the sustained reduction of VEGF. Therefore, due to the depletion of macrophages and the increase in HIF-1a, the mRNA expression of VEGF in the late stage of repair after macrophage depletion was lower than that after simple muscle contusion (Fig. 7b). Moreover, during all stages of repair after macrophage depletion, the mRNA expression of Angpt-1 was lower than that after simple muscle contusion (Fig. 7c). It is possible that repair impairment induced by macrophage depletion prolongs inflammation or aggravates fibrosis, leading to decreased angiogenesis and even competitive inhibition of Angpt-1 by Angpt-2 (70).

Furthermore, compared with that after macrophage depletion, the mRNA expression of HIF-1a was reduced significantly during all stages of repair after IGF-1 injection (Fig. 7a). This might be because IGF1 enhanced the stabilization and activity of HIF-1a by regulating the synthesis of HIF-1a protein $(59,71)$, thus inhibiting the increase in HIF-1a caused by macrophage depletion. Additionally, the increased expression of VEGF in the late stage and Angpt-1 during all stages of repair after IGF-1 injection (Fig. 7b, c) suggests that IGF-1 injection might partly improve the inhibition of angiogenesis regulatory factors induced by macrophage depletion. Moreover, the mRNA expression of HIF-1a, VEGF and Angpt-1 in the late stage of repair was lower than that after simple muscle contusion (Fig. 7a-c), suggesting that even IGF-1 injection following macrophage depletion ultimately could not promote angiogenesis and the impaired repair of contused muscle to a similar degree as after simple muscle contusion.

\section{Conclusions}

In brief, if the macrophages had been depleted continuously, IGF-1 injection could have promoted partial recovery of macrophage subpopulations (CD206) and expression of VEGF and Angpt-1; But IGF-1 injection could not completely remedy the important role of macrophages in muscle regeneration-related 
regulatory factors, myogenic regulatory factors, and angiogenesis regulatory factors; IGF-1 injection into contusion skeletal muscle in the state of macrophage depletion could not improve the level of muscle regeneration and fibrosis, which was related to the failure of IGF-1 injection to improve the coordination of macrophage subsets and to promote angiogenesis to reach the level of simple muscle contusion (Fig. 8). Consequently, exogenic supplementation with IGF-1 did not improve the impaired regeneration and repair of contused muscle induced by macrophage depletion.

\section{Abbreviations}

$1 \mathrm{~d}$

Mice in this group were sampled at $1 \mathrm{~d}$ after contusion; $3 \mathrm{~d}$ :Mice in this group were sampled at $3 \mathrm{~d}$ after contusion; 7d:Mice in this group were sampled at 7d after contusion; 14d:Mice in this group were sampled at 14d after contusion; Angpt-1:Angiopoietin - 1; CD:Contusion and macrophage depletion; $\mathrm{CDI}$ :Contusion combining with macrophage depletion and IGF-1 injection; Con:Mice in this group were sampled before contusion; $\mathrm{Cp}$ :Contusion and placebo group; DAPI:4:6-diamidino-2-phenylindole; ECM:Extracellular matrix; GM or GMs:Gastrocnemius muscles; HIF-1a:Hypoxia inducible factor - 1a; IGF1 :Insulin-like growth factor -1 ; im:Intramuscular injection; ip:Intraperitoneal injection; M1:Proinflammatory type 1 macrophage; M2:Anti-inflammatory type 2 macrophage; MD:Macrophages depletion; MRFs:Myogenic regulatory factors; Myf5:Myogenic factor 5; Myf6:Myogenic factor 6; MyoD:Muscle differentiation factor; PBS:Phosphate-buffered saline; RT:Room temperature; RTPCR:Reverse transcription polymerase chain reaction; Rt-qPCR:Real-time quantitative PCR; SC:Satellite cell; SMC:Skeletal muscle cell; TBS:Trimethylolaminomethane buffer saline; VEGF:Vascular endothelial growth factor.

\section{Declarations}

The authors declare that they have no competing interests.

\section{Ethical approval}

All animal experiments in the present study were approved by the Ethics Review Committee for Animal Experimentation of Shanghai University of Sports (Reference No. 2014025).

\section{Funding}

This research was funded by the National Natural Science Foundation of China (Grant No. 31300975), the Natural Science Foundation of Shanghai (Grant No. 18ZR1437100), and the Key Lab of Development and Protection of Human Sports Ability in Shanghai (Grant No. 11DZ2261100).

\section{Author's contributions}


$W X$ and PC planned and supervised the project. ZZ carried out data analysis and drafted the manuscript. $Z Z, X L, L I Z, L f Z$, and $Y Z$ performed the experiments. $Z Z, X L, W X$ and $P C$ analyzed the data and revised the manuscript. $P C$ and $W X$ acquired the funding. All authors have read and approved the final version of the manuscript and submission.

\section{Author details}

${ }^{1}$ School of Kinesiology, Shanghai University of Sport, Shanghai 200438, China. ${ }^{2}$ College of Physical Education, Jinggangshan University, Jiangxi 343009, China. ${ }^{3}$ Research Center for Physical Fitness and Health Promotion of Adolescent, Guangzhou Sport University, Guangzhou 510500, China.

\section{References}

1. Tidball JG. Mechanisms of muscle injury, repair, and regeneration. Compr Physiol. 2011;1(4):202962.

2. Horie M, Enomoto M, Shimoda M, Okawa A, Miyakawa S, Yagishita K. Enhancement of satellite cell differentiation and functional recovery in injured skeletal muscle by hyperbaric oxygen treatment. $J$ Appl Physiol (1985). 2014;116(2):149-55.

3. Terada S, Ota S, Kobayashi M, Kobayashi T, Mifune Y, Takayama K, et al. Use of an antifibrotic agent improves the effect of platelet-rich plasma on muscle healing after injury. J Bone Joint Surg Am. 2013;95(11):980-8.

4. Kobayashi M, Ota S, Terada S, Kawakami Y, Otsuka T, Fu FH, et al. The Combined Use of Losartan and Muscle-Derived Stem Cells Significantly Improves the Functional Recovery of Muscle in a Young Mouse Model of Contusion Injuries. Am J Sports Med. 2016;44(12):3252-61.

5. Pelosi L, Giacinti C, Nardis C, Borsellino G, Rizzuto E, Nicoletti C, et al. Local expression of IGF-1 accelerates muscle regeneration by rapidly modulating inflammatory cytokines and chemokines. FASEB J. 2007;21(7):1393-402.

6. Luan X, Tian X, Zhang H, Huang R, Li N, Chen P, et al. Exercise as a prescription for patients with various diseases. J Sport Health Sci. 2019;8(5):422-41.

7. Liu XG, Xiao WH, Chen PJ, Zhao LL, Zeng ZG, Zhou YZ, et al. Depletion of Macrophage Impairs Skeletal Muscle Regeneration by Inhibited the Expression of Muscle Regeneration Regulatory Factors and Akt / mTOR Protein Synthesis Signaling Pathway. China Sport Science. 2018;38(3):48-56.

8. Liu X, Liu Y, Zhao L, Zeng Z, Xiao W, Chen P. Macrophage depletion impairs skeletal muscle regeneration: The roles of regulatory factors for muscle regeneration. Cell Biol Int. 2017;41(3):22838.

9. Vannella KM, Wynn TA. Mechanisms of Organ Injury and Repair by Macrophages. Annu Rev Physiol. 2017;79:593-617.

10. Eming SA, Wynn TA, Martin P. Inflammation and metabolism in tissue repair and regeneration. Science. 2017;356(6342):1026-30. 
11. Simkin J, Gawriluk TR, Gensel JC, Seifert AW. Macrophages are necessary for epimorphic regeneration in African spiny mice. Elife. 2017;6.

12. Tidball JG, Welc SS. Macrophage-Derived. IGF-1 Is a Potent Coordinator of Myogenesis and Inflammation in Regenerating Muscle. Mol Ther. 2015;23(7):1134-5.

13. Liu XG, Xu MM, Chen PJ, Xiao WH. The prospect and related mechanism of insulin-like growth factor1 in the treatment of skeletal muscle injury. Chemistry of Life. 2016;36(4):496-502.

14. Crisco JJ, Jokl P, Heinen GT, Connell MD, Panjabi MM. A muscle contusion injury model. Biomechanics, physiology, and histology. Am J Sports Med. 1994;22(5):702-10.

15. Kasemkijwattana C, Menetrey J, Somogyl G, Moreland MS, Fu FH, Buranapanitkit B, et al. Development of approaches to improve the healing following muscle contusion. Cell Transplant. 1998;7(6):585-98.

16. Nozaki M, Li Y, Zhu J, Ambrosio F, Uehara K, Fu FH, et al. Improved muscle healing after contusion injury by the inhibitory effect of suramin on myostatin, a negative regulator of muscle growth. Am J Sports Med. 2008;36(12):2354-62.

17. Wright-Carpenter T, Opolon P, Appell HJ, Meijer H, Wehling P, Mir LM. Treatment of muscle injuries by local administration of autologous conditioned serum: animal experiments using a muscle contusion model. Int J Sports Med. 2004;25(8):582-7.

18. Liu X, Zeng Z, Zhao L, Xiao W, Chen P. Changes in inflammatory and oxidative stress factors and the protein synthesis pathway in injured skeletal muscle after contusion. Exp Ther Med. 2018;15(2):2196-202.

19. Smith C, Kruger MJ, Smith RM, Myburgh KH. The inflammatory response to skeletal muscle injury: illuminating complexities. Sports Med. 2008;38(11):947-69.

20. Bere T, Alonso JM, Wangensteen A, Bakken A, Eirale C, Dijkstra HP, et al. Injury and illness surveillance during the 24th Men's Handball World Championship 2015 in Qatar. Br J Sports Med. 2015;49(17):1151-6.

21. Feeley BT, Kennelly S, Barnes RP, Muller MS, Kelly BT, Rodeo SA, et al. Epidemiology of National Football League training camp injuries from 1998 to 2007. Am J Sports Med. 2008;36(8):1597-603.

22. Summan M, Warren GL, Mercer RR, Chapman R, Hulderman T, Van Rooijen N, et al. Macrophages and skeletal muscle regeneration: a clodronate-containing liposome depletion study. Am J Physiol Regul Integr Comp Physiol. 2006;290(6):R1488-95.

23. Tyner JW, Uchida O, Kajiwara N, Kim EY, Patel AC, O'Sullivan MP, et al. CCL5-CCR5 interaction provides antiapoptotic signals for macrophage survival during viral infection. Nat Med. 2005;11(11):1180-7.

24. Shen W, Li Y, Zhu J, Schwendener R, Huard J. Interaction between macrophages, TGF-beta1, and the COX-2 pathway during the inflammatory phase of skeletal muscle healing after injury. $\mathrm{J}$ Cell Physiol. 2007;214(2):405-12.

25. Xiao W, Liu Y, Chen P. Macrophage Depletion Impairs Skeletal Muscle Regeneration: the Roles of Profibrotic Factors, Inflammation, and Oxidative Stress. Inflammation. 2016;39(6):2016-28. 
26. Lu H, Huang D, Saederup N, Charo IF, Ransohoff RM, Zhou L. Macrophages recruited via CCR2 produce insulin-like growth factor-1 to repair acute skeletal muscle injury. FASEB J. 2011;25(1):35869.

27. Chan YS, Li Y, Foster W, Horaguchi T, Somogyi G, Fu FH, et al. Antifibrotic effects of suramin in injured skeletal muscle after laceration. J Appl Physiol (1985). 2003;95(2):771-80.

28. Mills P, Dominique JC, Lafreniere JF, Bouchentouf M, Tremblay JP. A synthetic mechano growth factor E Peptide enhances myogenic precursor cell transplantation success. Am J Transplant. 2007;7(10):2247-59.

29. Hwang JH, Ra YJ, Lee KM, Lee JY, Ghil SH. Therapeutic effect of passive mobilization exercise on improvement of muscle regeneration and prevention of fibrosis after laceration injury of rat. Arch Phys Med Rehabil. 2006;87(1):20-6.

30. Sisson TH, Nguyen MH, Yu B, Novak ML, Simon RH, Koh TJ. Urokinase-type plasminogen activator increases hepatocyte growth factor activity required for skeletal muscle regeneration. Blood. 2009;114(24):5052-61.

31. Koh TJ, Bryer SC, Pucci AM, Sisson TH. Mice deficient in plasminogen activator inhibitor-1 have improved skeletal muscle regeneration. Am J Physiol Cell Physiol. 2005;289(1):C217-23.

32. Chirgwin JM, Przybyla AE, MacDonald RJ, Rutter WJ. Isolation of biologically active ribonucleic acid from sources enriched in ribonuclease. Biochemistry. 1979;18(24):5294-9.

33. Livak KJ, Schmittgen TD. Analysis of relative gene expression data using real-time quantitative PCR and the 2(-Delta Delta C(T)) Method. Methods. 2001;25(4):402-8.

34. Singh DP, Barani Lonbani Z, Woodruff MA, Parker TJ, Steck R, Peake JM. Effects of Topical Icing on Inflammation, Angiogenesis, Revascularization, and Myofiber Regeneration in Skeletal Muscle Following Contusion Injury. Front Physiol. 2017;8:93.

35. Liu XG, Chen PJ, Zhao LL, Zeng ZG, Xiao WH. Macrophages depletion impairs skeletal muscle regeneration by regulating inflammation and oxidative stress levels. Sheng Li Xue Bao. 2018;70(1):23-32.

36. Bryer SC, Fantuzzi G, Van Rooijen N, Koh TJ. Urokinase-type plasminogen activator plays essential roles in macrophage chemotaxis and skeletal muscle regeneration. Journal of immunology. 2008;180(2):1179-88.

37. Tidball JG, Wehling-Henricks M. Macrophages promote muscle membrane repair and muscle fibre growth and regeneration during modified muscle loading in mice in vivo. J Physiol. 2007;578(Pt 1):327-36.

38. Murray PJ, Wynn TA. Protective and pathogenic functions of macrophage subsets. Nat Rev Immunol. 2011;11(11):723-37.

39. Wynn TA, Vannella KM. Macrophages in Tissue Repair, Regeneration, and Fibrosis. Immunity. 2016;44(3):450-62.

40. Lu W, Fu C, Song L, Yao Y, Zhang X, Chen Z, et al. Exposure to supernatants of macrophages that phagocytized dead mesenchymal stem cells improves hypoxic cardiomyocytes survival. Int $J$ 
Cardiol. 2013;165(2):333-40.

41. Lu H, Huang D, Ransohoff RM, Zhou L. Acute skeletal muscle injury: CCL2 expression by both monocytes and injured muscle is required for repair. FASEB J. 2011;25(10):3344-55.

42. Hernandez-Hernandez JM, Garcia-Gonzalez EG, Brun CE, Rudnicki MA. The myogenic regulatory factors, determinants of muscle development, cell identity and regeneration. Semin Cell Dev Biol. 2017;72:10-8.

43. McClure MJ, Clark NM, Hyzy SL, Chalfant CE, Olivares-Navarrete R, Boyan BD, et al. Role of integrin alpha7beta1 signaling in myoblast differentiation on aligned polydioxanone scaffolds. Acta Biomater. 2016;39:44-54.

44. Zammit PS. Function of the myogenic regulatory factors Myf5, MyoD, Myogenin and MRF4 in skeletal muscle, satellite cells and regenerative myogenesis. Semin Cell Dev Biol. 2017;72:19-32.

45. Aguera E, Castilla S, Luque E, Jimena I, Ruz-Caracuel I, Leiva-Cepas F, et al. Denervated muscle extract promotes recovery of muscle atrophy through activation of satellite cells. An experimental study. J Sport Health Sci. 2019;8(1):23-31.

46. Liu HH, Wang JW, Zhang RP, Chen X, Yu HY, Jin HB, et al. In ovo feeding of IGF-1 to ducks influences neonatal skeletal muscle hypertrophy and muscle mass growth upon satellite cell activation. J Cell Physiol. 2012;227(4):1465-75.

47. Zanou N, Gailly P. Skeletal muscle hypertrophy and regeneration: interplay between the myogenic regulatory factors (MRFs) and insulin-like growth factors (IGFs) pathways. Cell Mol Life Sci. 2013;70(21):4117-30.

48. Wynn TA, Barron L. Macrophages: master regulators of inflammation and fibrosis. Semin Liver Dis. 2010;30(3):245-57.

49. Li Q, Zheng M, Liu Y, Sun W, Shi J, Ni J, et al. A pathogenetic role for M1 macrophages in peritoneal dialysis-associated fibrosis. Mol Immunol. 2018;94:131-9.

50. Kratochvill F, Neale G, Haverkamp JM, Van de Velde LA, Smith AM, Kawauchi D, et al. TNF Counterbalances the Emergence of M2 Tumor Macrophages. Cell Rep. 2015;12(11):1902-14.

51. Duffield JS, Lupher M, Thannickal VJ, Wynn TA. Host responses in tissue repair and fibrosis. Annu Rev Pathol. 2013;8:241-76.

52. Pesce JT, Ramalingam TR, Mentink-Kane MM, Wilson MS, El Kasmi KC, Smith AM, et al. Arginase-1expressing macrophages suppress Th2 cytokine-driven inflammation and fibrosis. PLoS Pathog. 2009;5(4):e1000371.

53. Murray PJ, Rathmell J, Pearce E, SnapShot. Immunometabolism Cell Metab. 2015;22(1):190-e1.

54. Tonkin J, Temmerman L, Sampson RD, Gallego-Colon E, Barberi L, Bilbao D, et al. Monocyte/Macrophage-derived IGF-1 Orchestrates Murine Skeletal Muscle Regeneration and Modulates Autocrine Polarization. Mol Ther. 2015;23(7):1189-200.

55. Murray PJ, Wynn TA. Obstacles and opportunities for understanding macrophage polarization. J Leukoc Biol. 2011;89(4):557-63. 
56. Galli SJ, Borregaard N, Wynn TA. Phenotypic and functional plasticity of cells of innate immunity: macrophages, mast cells and neutrophils. Nat Immunol. 2011;12(11):1035-44.

57. Cho Y, Shin JE, Ewan EE, Oh YM, Pita-Thomas W, Cavalli V. Activating Injury-Responsive Genes with Hypoxia Enhances Axon Regeneration through Neuronal HIF-1 alpha. Neuron. 2015;88(4):720-34.

58. Zhang Y, Strehin I, Bedelbaeva K, Gourevitch D, Clark L, Leferovich J, et al. Drug-induced regeneration in adult mice. Sci Transl Med. 2015;7(290):290ra92.

59. Andrikopoulou E, Zhang X, Sebastian R, Marti G, Liu L, Milner SM, et al. Current Insights into the role of HIF-1 in cutaneous wound healing. Curr Mol Med. 2011;11(3):218-35.

60. Imanishi M, Tomita S, Ishizawa K, Kihira Y, Ueno M, Izawa-Ishizawa Y, et al. Smooth muscle cellspecific Hif-1 alpha deficiency suppresses angiotensin II-induced vascular remodelling in mice. Cardiovasc Res. 2014;102(3):460-8.

61. Apte RS, Chen DS, Ferrara N. VEGF in Signaling and Disease: Beyond Discovery and Development. Cell. 2019;176(6):1248-64.

62. Goel HL, Mercurio AM. VEGF targets the tumour cell. Nat Rev Cancer. 2013;13(12):871-82.

63. Lange C, Storkebaum E, de Almodovar CR, Dewerchin M, Carmeliet P. Vascular endothelial growth factor: a neurovascular target in neurological diseases. Nat Rev Neurol. 2016;12(8):439-54.

64. Dulak J, Jozkowicz A. Regulation of vascular endothelial growth factor synthesis by nitric oxide: facts and controversies. Antioxid Redox Signal. 2003;5(1):123-32.

65. Ameln H, Gustafsson T, Sundberg CJ, Okamoto K, Jansson E, Poellinger L, et al. Physiological activation of hypoxia inducible factor-1 in human skeletal muscle. FASEB J. 2005;19(8):1009-11.

66. Jain T, Nikolopoulou EA, Xu Q, Qu A. Hypoxia inducible factor as a therapeutic target for atherosclerosis. Pharmacol Ther. 2018;183:22-33.

67. Wu D, Cao W, Xiang D, Hu YP, Luo B, Chen P. Exercise induces tissue hypoxia and HIF-1alpha redistribution in the small intestine. J Sport Health Sci. 2020;9(1):82-9.

68. Denapoli PM, Stilhano RS, Ingham SJ, Han SW, Abdalla RJ. Platelet-Rich Plasma in a Murine Model: Leukocytes, Growth Factors, Flt-1, and Muscle Healing. Am J Sports Med. 2016;44(8):1962-71.

69. Gao X, Wang YS, Li XQ, Hou HY, Su JB, Yao LB, et al. Macrophages promote vasculogenesis of retinal neovascularization in an oxygen-induced retinopathy model in mice. Cell Tissue Res. 2016;364(3):599-610.

70. Fagiani E, Christofori G. Angiopoietins in angiogenesis. Cancer letters. 2013;328(1):18-26.

71. Fukuda R, Hirota K, Fan F, Jung YD, Ellis LM, Semenza GL. Insulin-like growth factor 1 induces hypoxia-inducible factor 1-mediated vascular endothelial growth factor expression, which is dependent on MAP kinase and phosphatidylinositol 3-kinase signaling in colon cancer cells. J Biol Chem. 2002;277(41):38205-11.

\section{Figures}




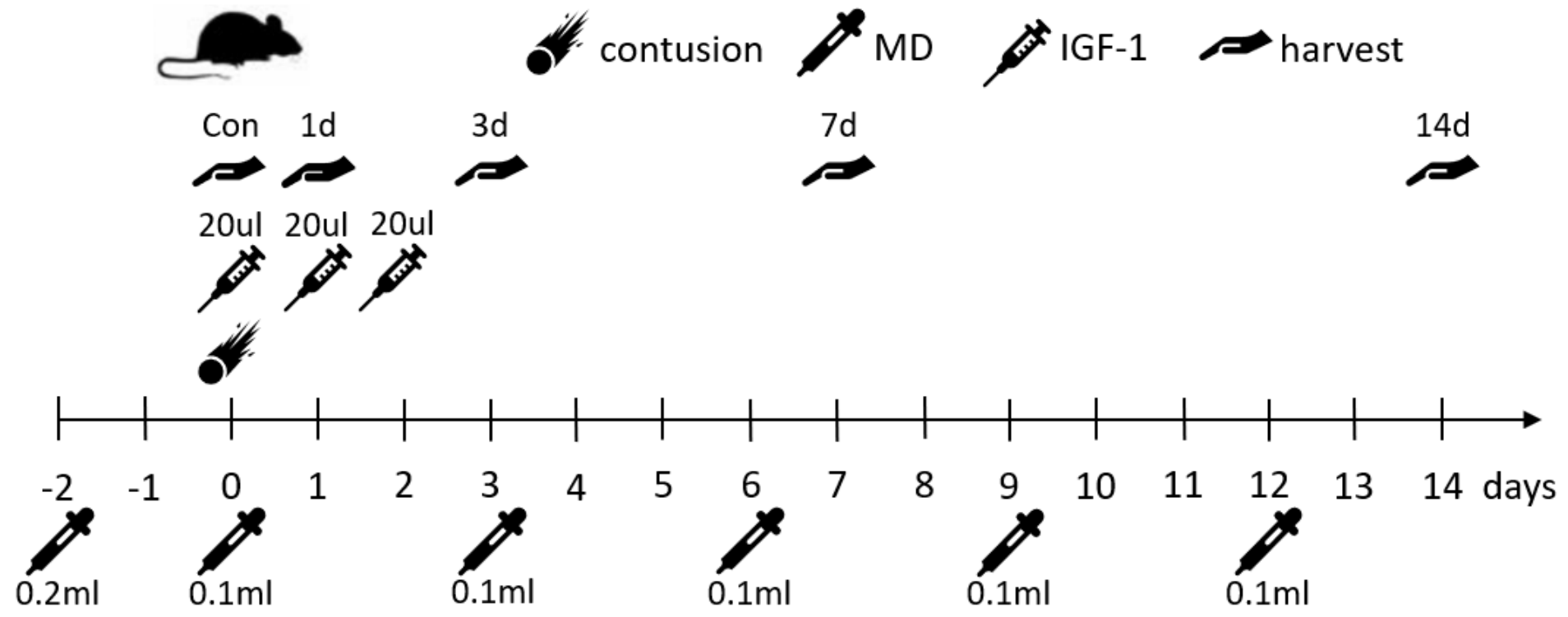

Figure 1

Schematic representation of the experimental timeline. MD, macrophages depletion (clodronate liposomes intraperitoneal injection). IGF-1, recombinant mouse IGF-I protein (intramuscular injection). Con, mice in this group were sampled before contusion; $1 \mathrm{~d}$, mice in this group were sampled at $1 \mathrm{~d}$ after contusion; $3 \mathrm{~d}$, mice in this group were sampled at 

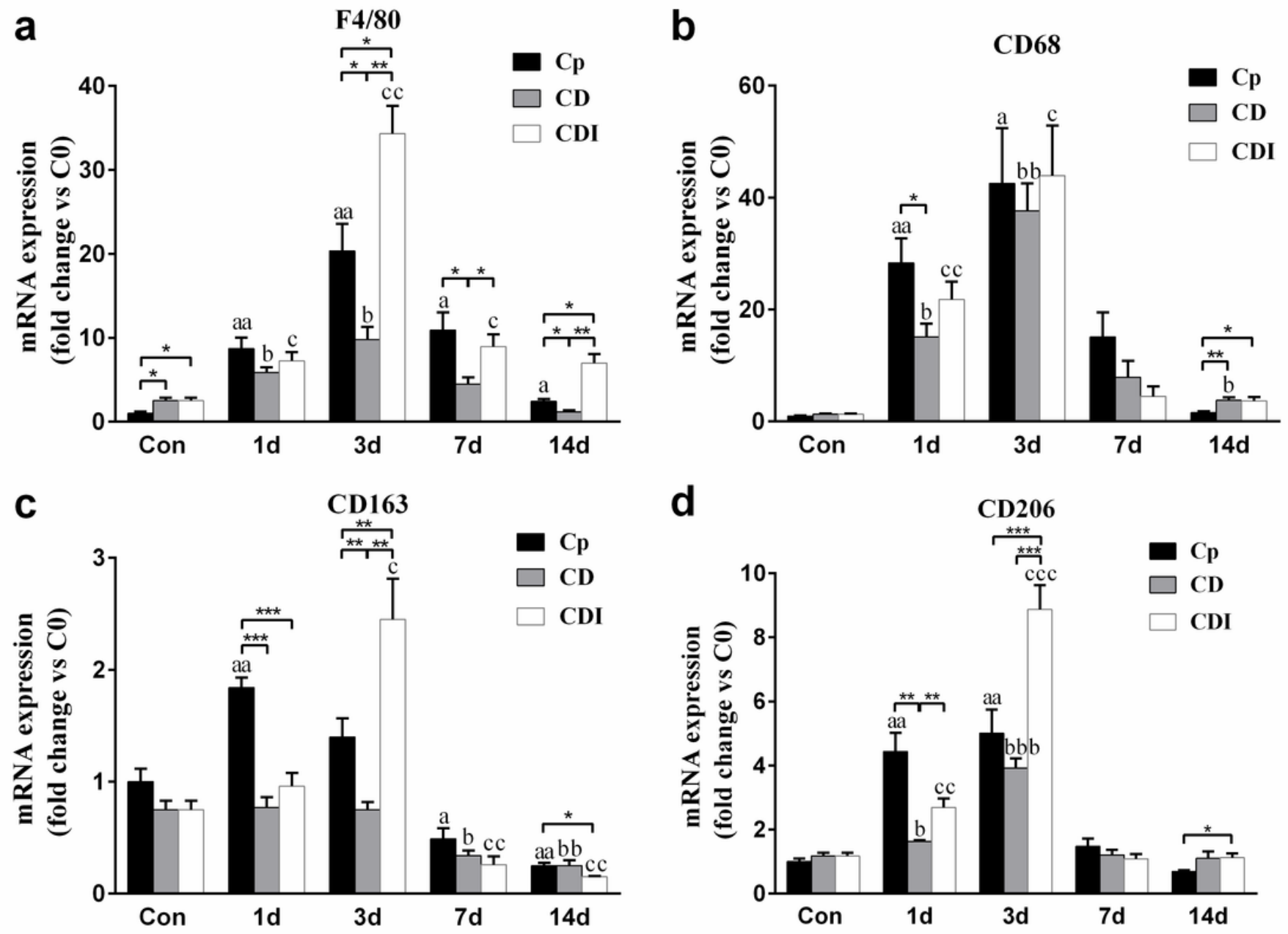

Figure 2

mRNA levels of the specific markers of macrophages at Con, $1 \mathrm{~d}, 3 \mathrm{~d}, 7 \mathrm{~d}, 14 \mathrm{~d}$ after muscle contusion in Cp, CD and CDI groups. (a) The expression of F4/80; (b) The expression of CD68; (c) The expression of CD163; (d) The expression of CD206. Cp, contusion and placebo treatment; CD, contusion and macrophages depletion; CDI, contusion with macrophages depletion and IGF-1 injection. ${ }^{*} \rho \leq 0.05$; ${ }^{\star \star} \rho \leq$ $0.01 ; * \star \star \rho \leq 0.001$ compared among $C p, C D, C D I$ groups. a $\rho \leq 0.05$; aa $\rho \leq 0.01$ compared to Con in $\mathrm{Cp}$ group; $b \rho \leq 0.05$; bb $\rho \leq 0.01$; bbb $\rho \leq 0.001$ compared to Con in CD group; $c \rho \leq 0.05$; $c c \rho \leq 0.01$; $c c c \rho \leq$ 0.001 compared to Con in CDI group. 


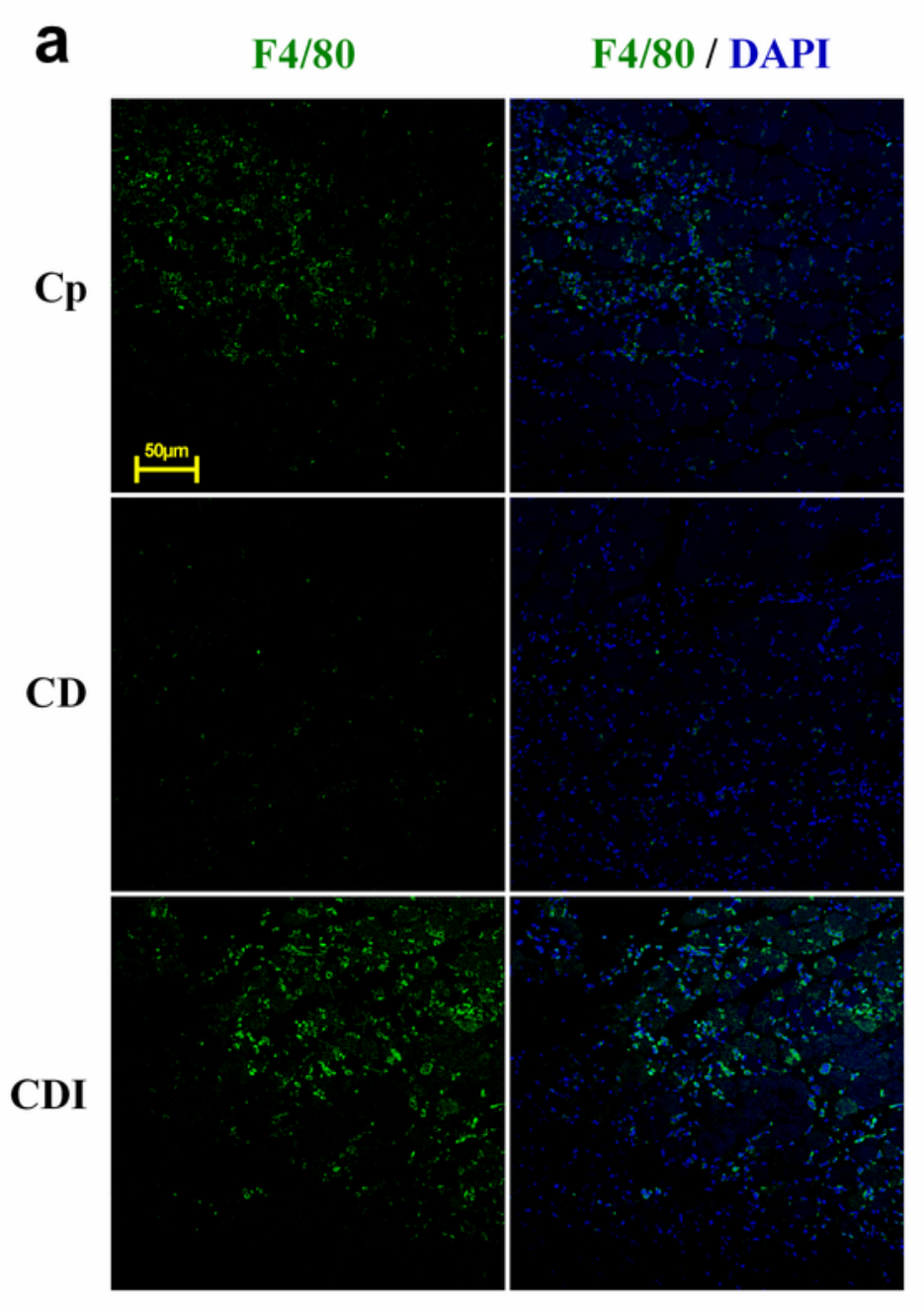

b

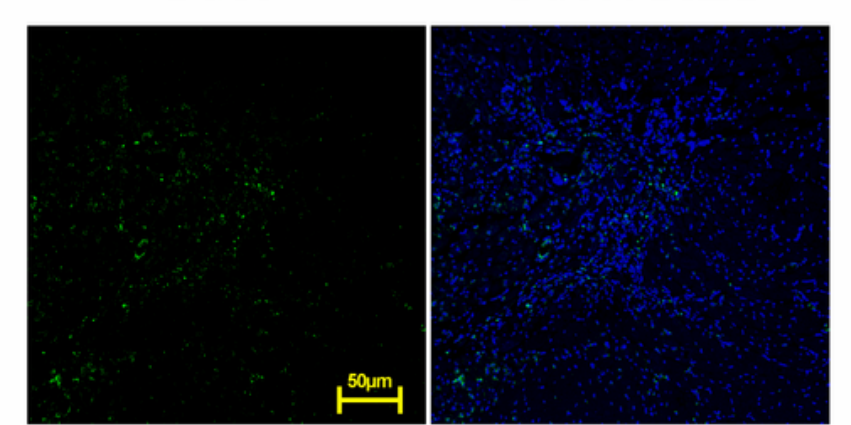

C

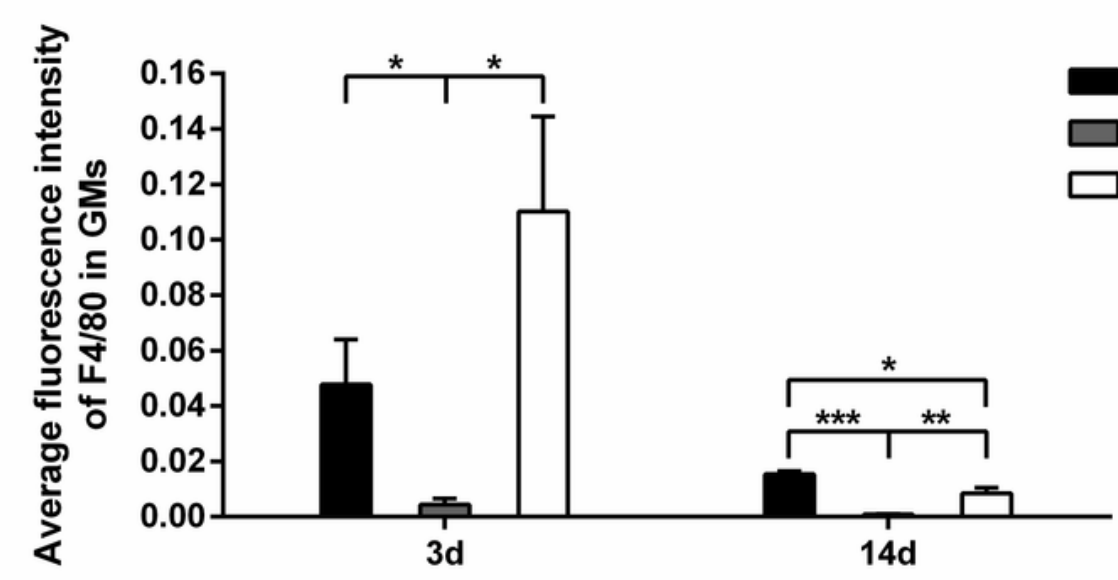

Figure 3

Immunofluorescence intensity of $\mathrm{F} 4 / 80$ at $3 \mathrm{~d}$ and $14 \mathrm{~d}$ after muscle contusion in $\mathrm{Cp}, \mathrm{CD}$ and $\mathrm{CDI}$ groups. (a) Histological evaluation of F4/80 expression at $3 \mathrm{~d}$ after contusion in $\mathrm{Cp}, \mathrm{CD}$ and $\mathrm{CDI}$ groups (immunofluorescence staining). (b) Histological evaluation of F4/80 expression at $14 \mathrm{~d}$ after contusion in $\mathrm{Cp}, \mathrm{CD}$ and $\mathrm{CDI}$ groups (immunofluorescence staining). F4/80 expressions were marked with green. DAPI marked with blue were defined as a cell nucleus. Bar=50 $\mu \mathrm{m}$. (c) Average fluorescence intensity of F4/80 
at $3 \mathrm{~d}$ and $14 \mathrm{~d}$ after contusion in $\mathrm{Cp}, \mathrm{CD}$ and CDI groups. ${ }^{\star} \rho \leq 0.05 ;{ }^{* \star} \rho \leq 0.01 ;{ }^{* \star} \rho \leq 0.001$ vs. Cp group. $\mathrm{Cp}$, contusion and placebo treatment; $\mathrm{CD}$, contusion and macrophages depletion; $\mathrm{CDI}$, contusion with macrophages depletion and IGF-1 injection.
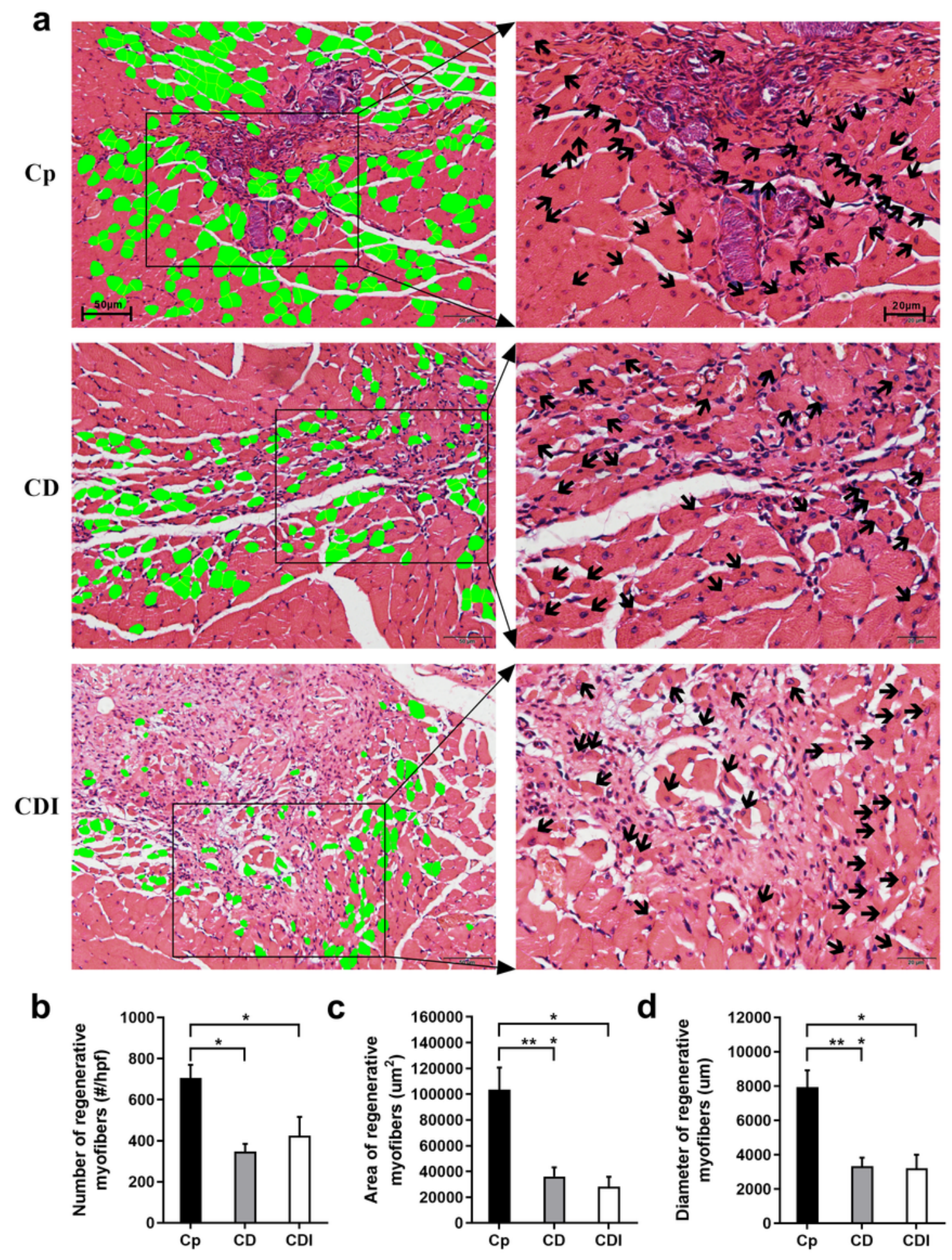

Figure 4

Muscle regeneration at $14 \mathrm{~d}$ after muscle contusion in $\mathrm{Cp}, \mathrm{CD}$ and $\mathrm{CDI}$ groups. (a) Histological evaluation of gastrocnemius muscle regeneration at $14 \mathrm{~d}$ after contusion in $\mathrm{Cp}, \mathrm{CD}$ and $\mathrm{CDI}$ groups (hematoxylin 
and eosin staining). The centrally-nucleated myofibers marked with green or $\uparrow$ were defined as regenerative myofibers. Left bar $=50 \mu \mathrm{m}$, Right bar $=20 \mu \mathrm{m}$. (b) Number (the total number, fibers/hpf) of regenerating myofibers at $14 \mathrm{~d}$ after contusion in $\mathrm{Cp}, \mathrm{CD}$ and CDI groups. (c) Area (the sum of crosssectional area, $\mu \mathrm{m} 2$ ) of regenerating myofibers at $14 \mathrm{~d}$ after contusion in $\mathrm{Cp}, \mathrm{CD}$ and $\mathrm{CDI}$ groups. (d) Diameter (the sumof the minor axis diameters, $\mu \mathrm{m}$ ) of regenerating myofibers at $14 \mathrm{~d}$ after contusion in $C p, C D$ and CDI groups. ${ }^{*} p \leq 0.05 ;{ }^{*} p \leq 0.01$ vs. Cp group. Cp, contusion and placebo treatment; $C D$, contusion and macrophages depletion; $\mathrm{CDI}$, contusion with macrophages depletion and IGF-1 injection. hpf: 200x high-powered fields.
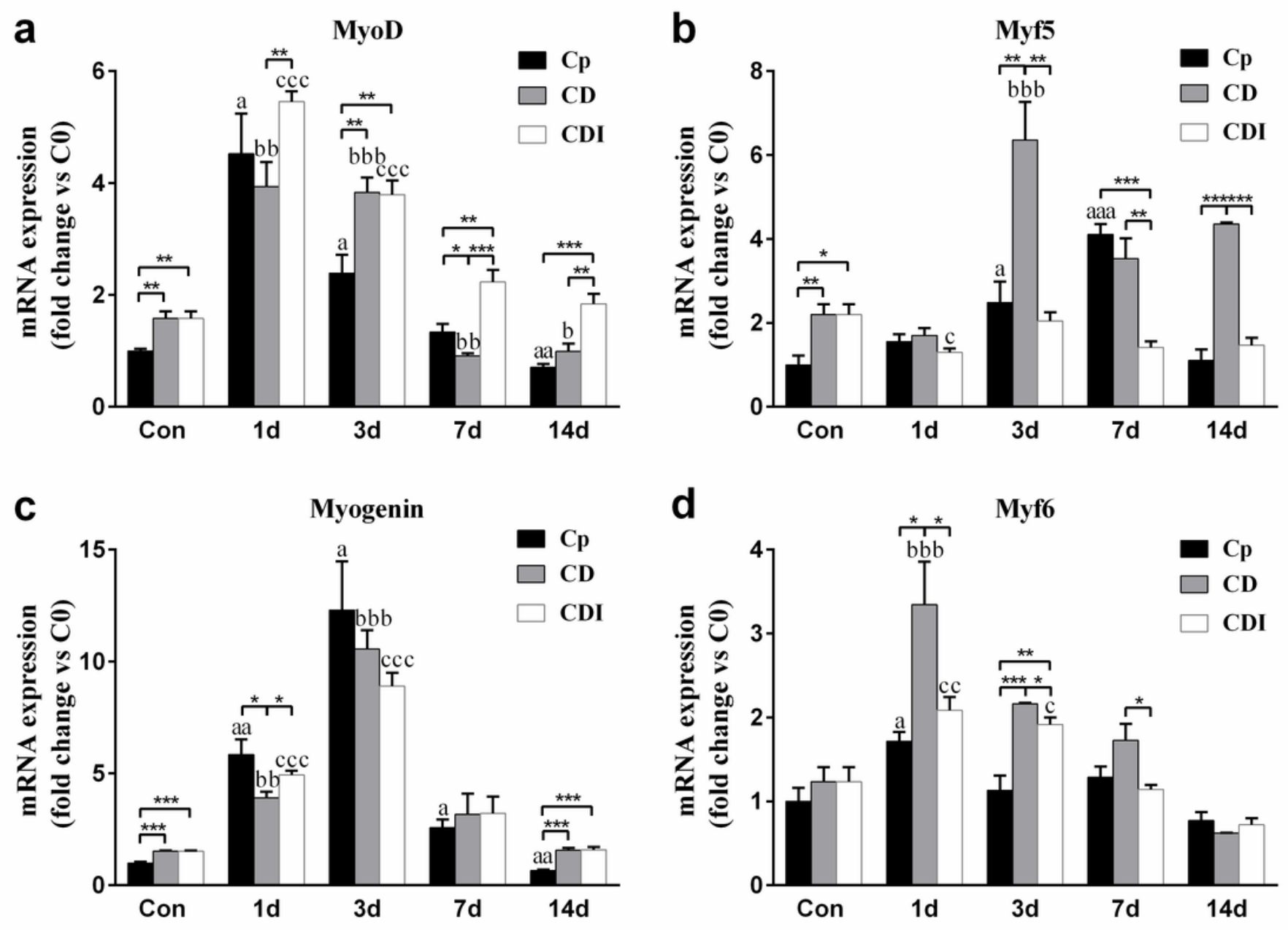

\section{Figure 5}

mRNA levels of myogenic regulatory factors at Con, $1 \mathrm{~d}, 3 \mathrm{~d}, 7 \mathrm{~d}, 14 \mathrm{~d}$ after muscle contusion in Cp, CD and CDI groups. (a) The expression of MyoD; (b) The expression of Myf5; (c) The expression of myogenin; (d) The expression of Myf6. Cp, contusion and placebo treatment; CD, contusion and macrophages depletion; CDI, contusion with macrophages depletion and IGF-1 injection. ${ }^{*} \rho \leq 0.05$; ${ }^{* \star} \rho \leq$ 0.01 ; ${ }^{* \star} \rho \leq 0.001$ compared among $C p, C D, C D I$ groups. a $\rho \leq 0.05$; aa $\rho \leq 0.01$; aaa $\rho \leq 0.001$ compared to Con in Cp group; $b \rho \leq 0.05$; bb $\rho \leq 0.01$; bbb $\rho \leq 0.001$ compared to Con in $C D$ group; $c \rho \leq 0.05$; $c c \rho \leq$ 0.01 ; $\operatorname{ccc} \rho \leq 0.001$ compared to Con in CDI group. 


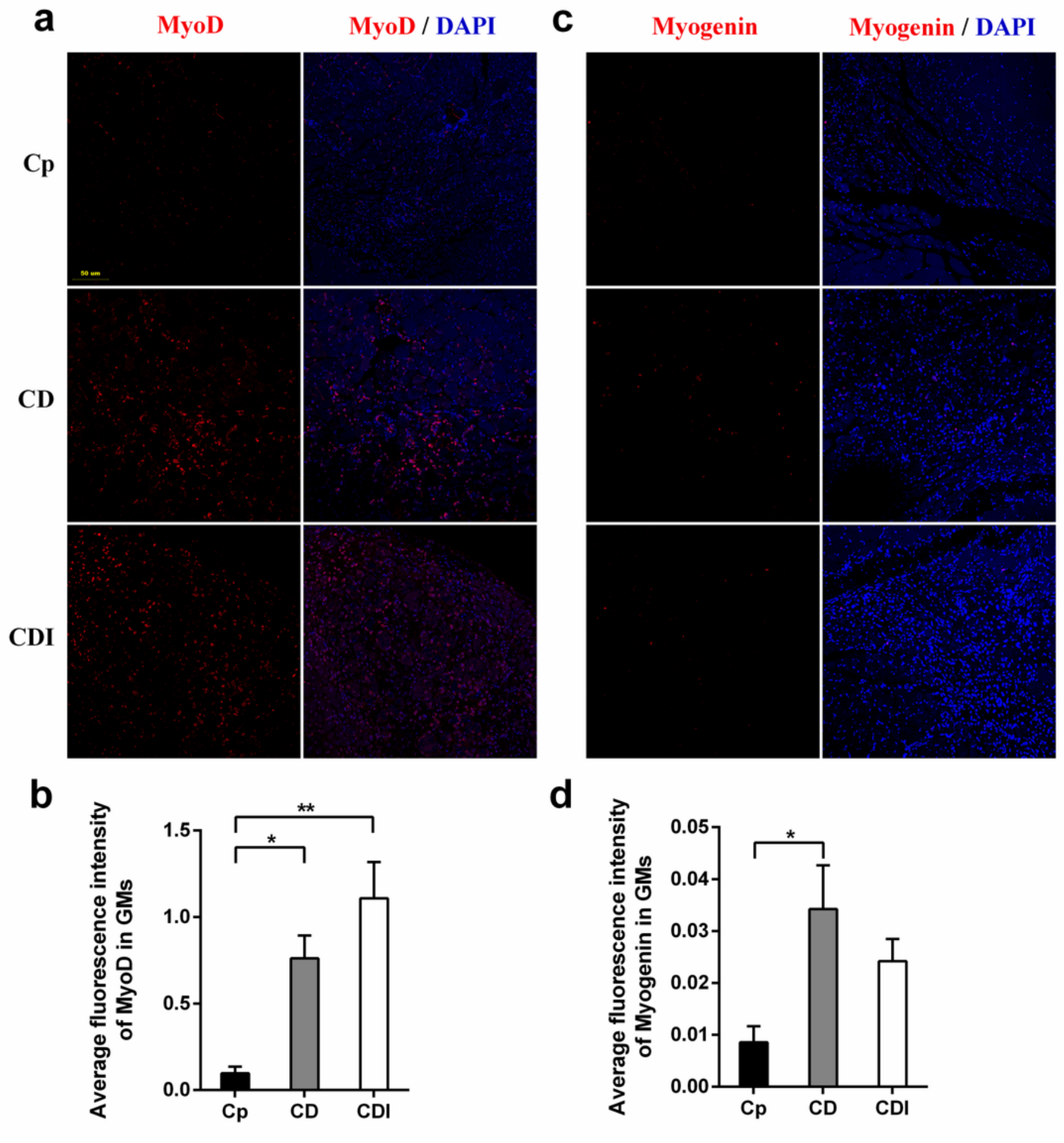

Figure 6

Immunofluorescence intensity of MyoD and myogenin at $14 \mathrm{~d}$ after muscle contusion in $\mathrm{Cp}, \mathrm{CD}$ and $\mathrm{CDI}$ groups. (a) and (c) Histological evaluation of MyoD and myogenin expression at $14 \mathrm{~d}$ after contusion in $\mathrm{Cp}, \mathrm{CD}$ and CDI groups (immunofluorescence staining). MyoD and myogenin expressions were marked with red. DAPI marked with blue were defined as a cell nucleus. Bar $=50 \mu \mathrm{m}$. (b) and (d) Average fluorescence intensity of MyoD and myogenin at $14 \mathrm{~d}$ after contusion in $\mathrm{Cp}, \mathrm{CD}$ and CDI groups. ${ }^{*} \mathrm{~s}$ 
$0.05 ;{ }^{\star \star} \rho \leq 0.01$ vs. Cp group. Cp, contusion and placebo treatment; $C D$, contusion and macrophages depletion; CDI, contusion with macrophages depletion and IGF-1 injection.
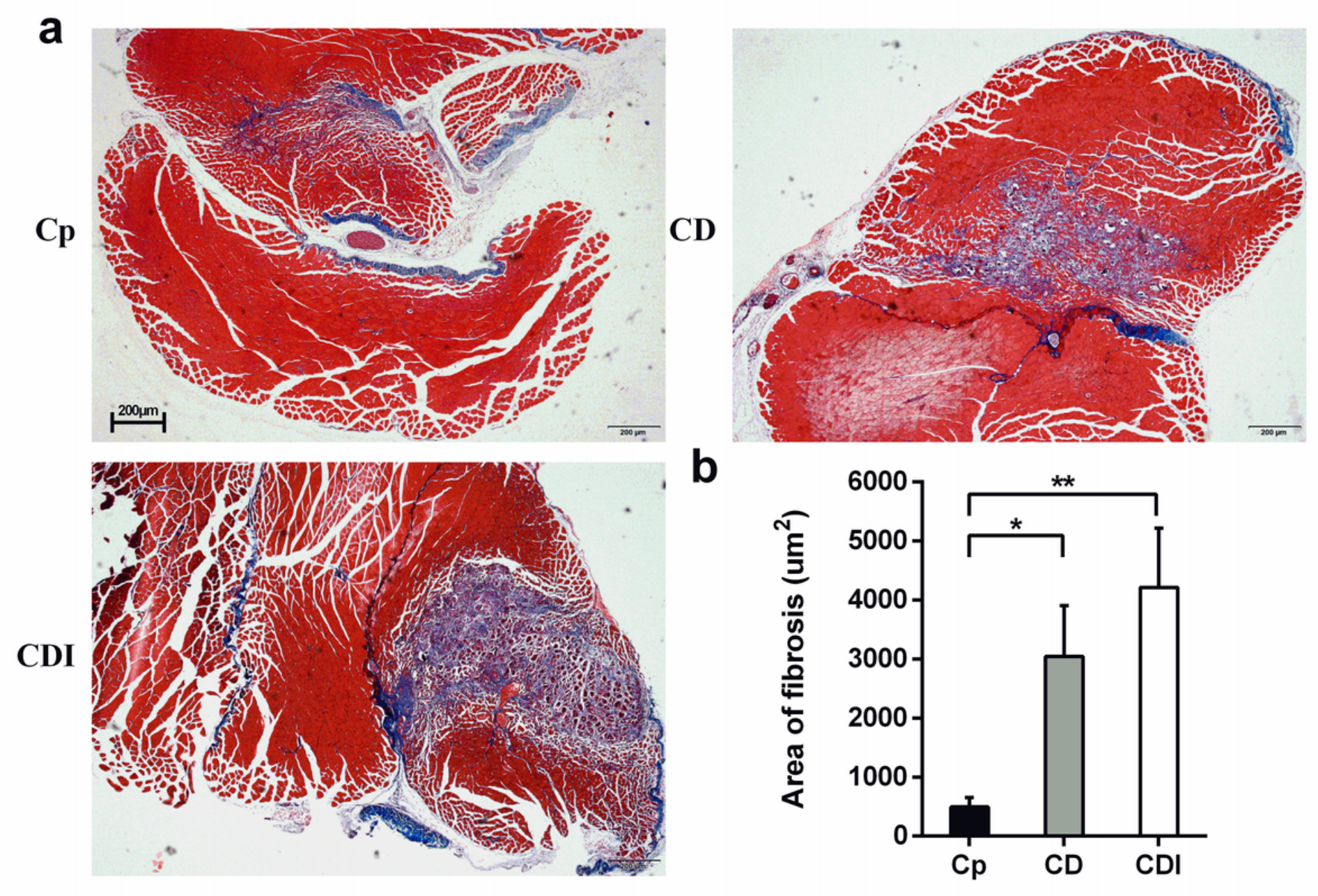

b

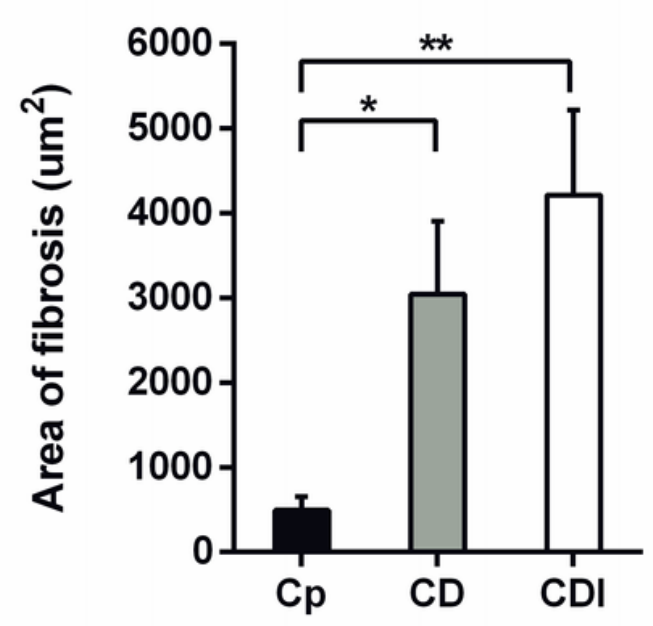

Figure 7

Muscle fibrosis at $14 \mathrm{~d}$ after muscle contusion in $\mathrm{Cp}, \mathrm{CD}$ and CDI groups. (a) Histological evaluation of fibrotic tissue at $14 \mathrm{~d}$ after contusion in $\mathrm{Cp}, \mathrm{CD}$ and $\mathrm{CDI}$ groups (Masson trichrome stain, collagen: blue;

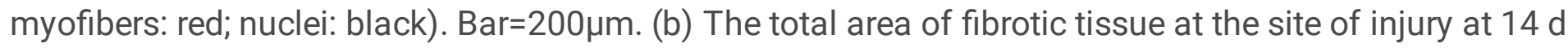
after contusion in $\mathrm{Cp}, \mathrm{CD}$ and $\mathrm{CDI}$ groups. ${ }^{*} p \leq 0.05 ;{ }^{*} p \leq 0.01$ vs. Cp group. $\mathrm{Cp}$, contusion and placebo treatment; $\mathrm{CD}$, contusion and macrophages depletion; $\mathrm{CDI}$, contusion with macrophages depletion and IGF-1 injection. 
a

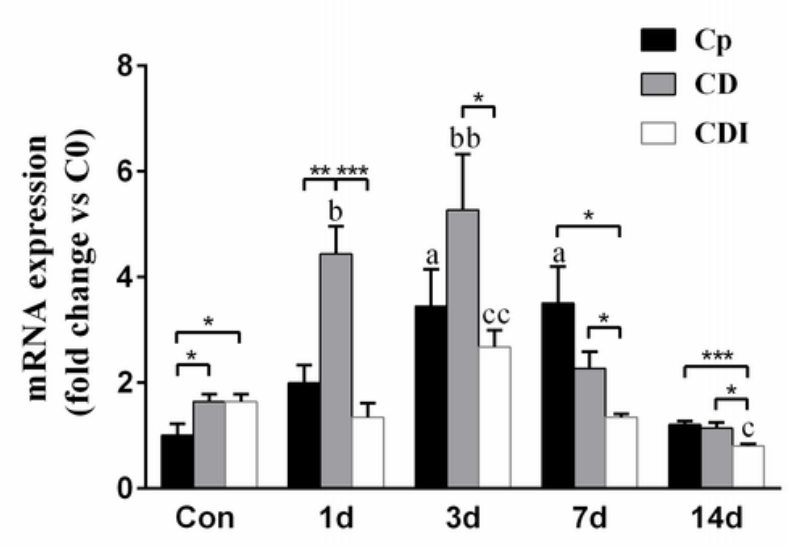

b

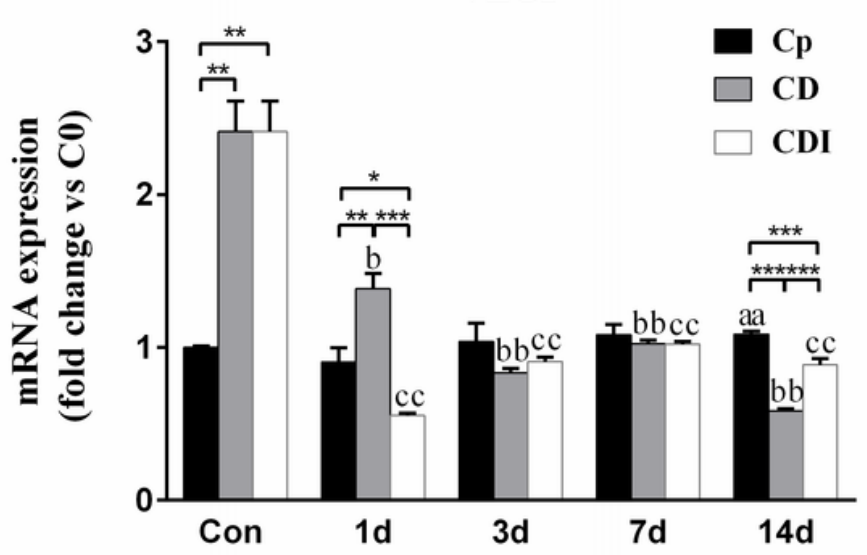

C

Angpt-1

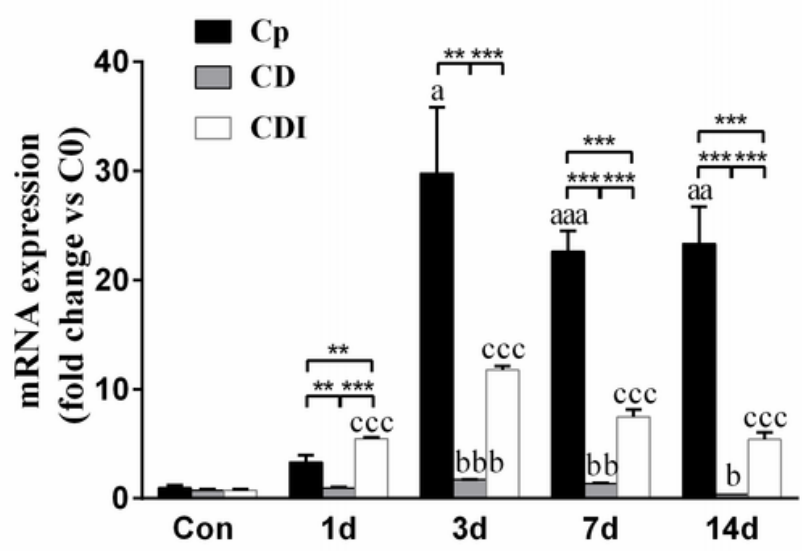

Figure 8

mRNA levels of angiogenesis regulatory factors at Con, $1 \mathrm{~d}, 3 \mathrm{~d}, 7 \mathrm{~d}, 14 \mathrm{~d}$ after muscle contusion in $\mathrm{Cp}$, CD and CDI groups. (a) The expression of HIF-1a; (b) The expression of VEGF; (c) The expression of Angpt-1. $\mathrm{Cp}$, contusion and placebo treatment; $\mathrm{CD}$, contusion and macrophages depletion; $\mathrm{CDI}$, contusion with macrophages depletion and IGF-1 injection. ${ }^{*} \rho \leq 0.05 ;{ }^{* *} \rho \leq 0.01 ;{ }^{* * *} \rho \leq 0.001$ compared among Cp, CD, CDI groups. a $\rho \leq 0.05$; aa $\rho \leq 0.01$; aaa $\rho \leq 0.001$ compared to Con in Cp group; b $\rho \leq 0.05$; bb $\rho \leq$ 0.01 ; bbb $\rho \leq 0.001$ compared to Con in CD group; $c \rho \leq 0.05$; $c c \rho \leq 0.01$; $c c c \rho \leq 0.001$ compared to Con in CDI group. 


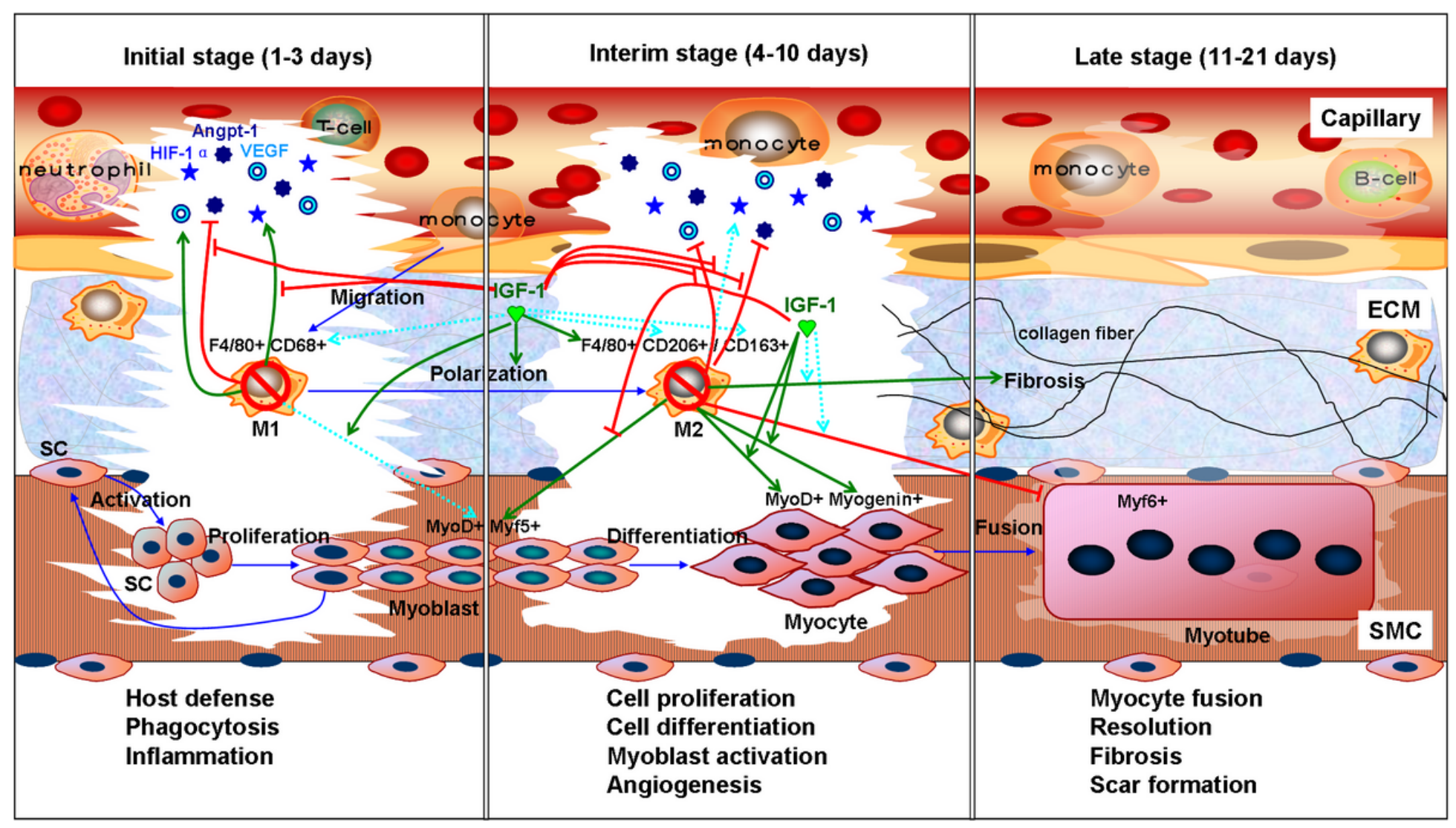

Figure 9

Schematic diagram of the effects of IGF-1 injection on the proliferation, differentiation and fusion of muscle satellite cells, muscle fibrosis, and angiogenesis, which affect the impaired regeneration of contused skeletal muscle caused by macrophage depletion. ECM: extracellular matrix; M1: proinflammatory type 1 macrophages; M2: anti-inflammatory type 2 macrophages; SC: satellite cell; SMC: skeletal muscle cell; : macrophage depletion; Dark blue arrows refer to the repair process of injured skeletal muscle; Green arrows refer to the promotion or enhancement; Red arrows refer to the inhibition or weakening; Light blue dotted arrows refer to weak or no effect. 